\title{
Dilatometric investigation of deformation mechanisms in polystyrene-polyethylene block copolymer blends. Correlation between Poisson ratio and adhesion
}

Citation for published version (APA):

Coumans, W. J., Heikens, D., \& Sjoerdsma, S. D. (1980). Dilatometric investigation of deformation mechanisms in polystyrene-polyethylene block copolymer blends. Correlation between Poisson ratio and adhesion. Polymer, 21(1), 103-108. https://doi.org/10.1016/0032-3861(80)90176-7

DOI:

10.1016/0032-3861(80)90176-7

Document status and date:

Published: 01/01/1980

Document Version:

Publisher's PDF, also known as Version of Record (includes final page, issue and volume numbers)

Please check the document version of this publication:

- A submitted manuscript is the version of the article upon submission and before peer-review. There can be important differences between the submitted version and the official published version of record. People interested in the research are advised to contact the author for the final version of the publication, or visit the DOI to the publisher's website.

- The final author version and the galley proof are versions of the publication after peer review.

- The final published version features the final layout of the paper including the volume, issue and page numbers.

Link to publication

\footnotetext{
General rights

- You may freely distribute the URL identifying the publication in the public portal. follow below link for the End User Agreement:

www.tue.nl/taverne

\section{Take down policy}

If you believe that this document breaches copyright please contact us at:

openaccess@tue.nl

providing details and we will investigate your claim.
}

Copyright and moral rights for the publications made accessible in the public portal are retained by the authors and/or other copyright owners and it is a condition of accessing publications that users recognise and abide by the legal requirements associated with these rights.

- Users may download and print one copy of any publication from the public portal for the purpose of private study or research.

- You may not further distribute the material or use it for any profit-making activity or commercial gain

If the publication is distributed under the terms of Article 25fa of the Dutch Copyright Act, indicated by the "Taverne" license above, please 


\title{
Dilatometric investigation of deformation mechanisms in polystyrene-polyethylene block copolymer blends: correlation between Poisson ratio and adhesion
}

\author{
W. Jan Coumans, Derk Heikens and S. Dirk Sjoerdsma \\ Eindhoven University of Technology, Laboratory of Polymer Technology, P. O. Box 513, \\ 5600 MB Eindhoven, The Netherlands \\ (Received 8 February 1979; revised 25 June 1979)
}

\begin{abstract}
To gain more insight into the deformation behaviour of blends containing polystyrene (PS), low density polyethylene(IdPE) and a PS-PE block copolymer, tensile tests have been performed with simultaneous volume measurements. Assuming that shearing does not give rise to volume changes, it is shown that, after yielding, crazing is the only deformation mechanism of blends with a low PE and PS-PE block copolymer content. Shearing becomes important at relatively high copolymer concentrations. This is explained by the formation of a semi-continuous low-modulus phase. The decrease of the Poisson ratio with PE content in PS-PE blends, as opposed to an increase if some block copolymer has been added to these blends, shows that the Poisson ratio is very sensitive to adhesion between the components. Toughness of PS-PE blends is discussed in terms of concentrations of craze nuclei. Too few craze nuclei give rise to brittle failure: the resulting low number of crazes cannot take over much of the deformation of the matrix. Too many craze nuclei cause brittle failure because chances are high that some of the high number of crazes formed will combine to produce a fatal crack. Therefore high toughness is only obtained at intermediate craze nuclei concentrations. The concentration of craze nuclei is shown to be dependent on the number of dispersed particles and the adhesion between these particles and the matrix.
\end{abstract}

\section{INTRODUCTION}

In earlier research ${ }^{1-8}$, normal block copolymers of polystyrene (PS) and polybutadiene (PB) and block copolymers of tapered structure containing a kind of random styrenebutadiene (SB) block between a PS block and a PB block were hydrogenated to become PS-polyolefine block copolymers. On addition of these block copolymers at concentrations of about $2 \%$ to polystyrene-low density polyethylene blends (PS-ldPE) in a melt blending operation, the range of dimensions of the spherical ldPE particles diminished from $10-40 \mu \mathrm{m}$ to $1-10 \mu \mathrm{m}$, indicating that the block copolymer was situated at the interphase between the IdPE particle and the PS matrix (Figure 1). Thus the block copolymers behaved as PS-ldPE block copolymers. In accord with this interpretation, the tensile strength and the yield stress of samples with these small concentrations (relative to the concentration of the IdPE) of normal and tapered block copolymers, were higher than that of corresponding PS-1dPE blends without copolymer. The scanning electron micrographs (SEM) of impact fracture surfaces of these samples showed craze planes and a high impact strength (Figure $2 a$ ).

However, at higher weight concentrations of the tapered block copolymers relative to those of IdPE, the fracture surfaces showed signs of microshear (Figure $2 b$ ). Micrographs showed that for blends which contained more than $20 \%$ of total dispersed phase, (semi-) continuous ldPE-BC phases appear to be formed with characteristic dimensions of about
$1 \mu \mathrm{m}$ in thickness and longer, (up to $10 \mu \mathrm{m}$ ), 'length'dimensions in cross-sections of samples.

Comparison of modulus-concentration behaviour of these samples with simple models indicated that at lower relative concentrations of $\mathrm{BC}$ to $\mathrm{ldPE}$, the block copolymer was at the interface between the ldPE particles and the PS matrix. At higher relative concentrations of $\mathrm{BC}$ to $\mathrm{ldPE}$ at total dispersed phase concentrations over $20 \%$, however, the excessively low modulus values indicated the presence of (semi-) continuous microphases also. It could be that this kind of semi-continuous region was where shearing took place (as observed at the fracture surfaces), whereas crazes could still be formed in the PS matrix.

To gain more insight into the deformation mechanism it became imperative to determine the contribution of crazing and microshearing to the deformation. Determination of volume changes during creep experiments is a good aid to distinguish shearing and crazing (Bucknall et al. ${ }^{9,10,11}$ ). This is because crazing produces a relative increase in volume proportional to the relative elongation, whereas the contribution of shearing to the volume change can be assumed to be negligible. As our investigation is directed to higher strain rates than used in the creep experiments mentioned above, it was necessary to develop a dilatometer for use with a tensile tester. It must be remarked here that the volume changes during tensile test can only arise from craze formation. Void formation in the soft phase in rubber modified PVC (as found by Heat et al. ${ }^{11}$ ), has never been observed in PS-ldPE blends. 


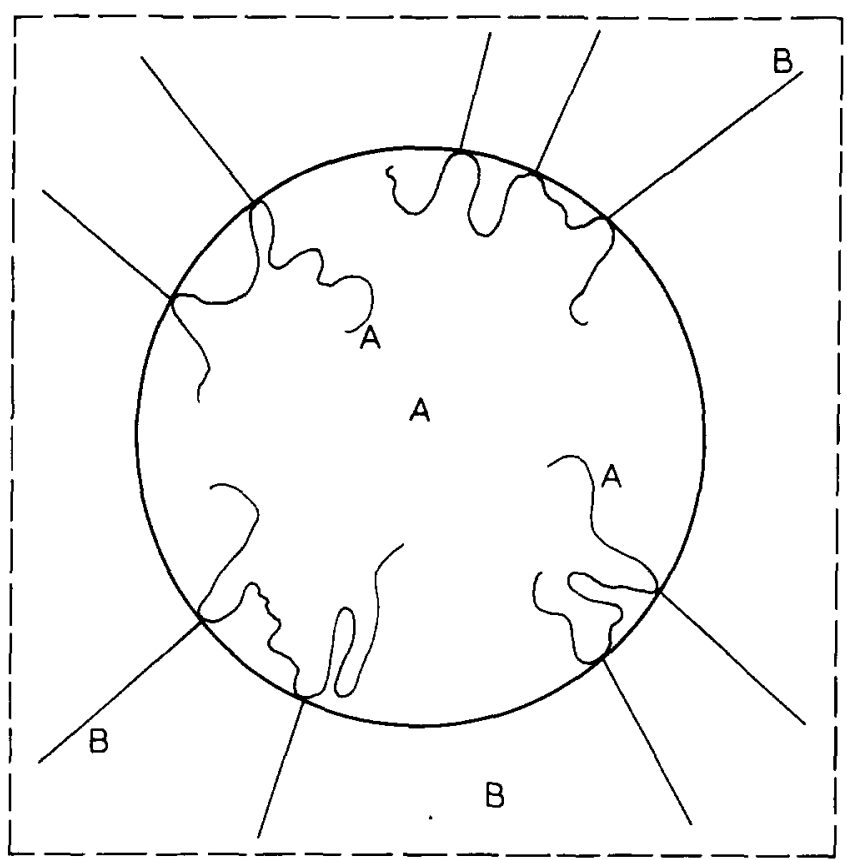

Figure 1 A particle of low density polyethylene $(A)$ dispersed in the matrix of polystyrene (B) with block copolymer at the interphase

\section{EXPERIMENTAL}

\section{The dilatometer}

A detailed description will be published elsewhere, but some general principles will be given here. The dilatometer allows continuous determination of the volume change of a sample during its elongation on an Instron Tensile Testing instrument. This is done by measuring the waterlevel in a capillary $\mathrm{G}$, attached to the vessel $\mathrm{A}$, enclosing the sample (Figure 3). The load is measured by the Instron instrument. The elongation of the sample $B$ is measured by following the displacement of the lower sample-clamp, attached to bar E, and the vesselbottom relative to compensation bar $F$ connected to the upper stationary clamp C. On an xyy' plotter, load and volume change are recorded simultaneously as a function of elongation.

The tension test specimens were rectangular unoriented compression moulded bars, with a span of $50 \mathrm{~mm}$ and crosssectional dimensions of $13 \times 3 \mathrm{~mm}$. Because of ill-defined elongation, dumbbell-shaped specimens are not suited for dilatometric measurements in the mentioned apparatus. As an example the experimental curves of one sample of high impact PS (Styron 453 naturel, Dow Chemical) are reproduced in Figure 4. The slope of the volume strain curve is related to the Poisson ratio $\nu$ of the isotropic system by the equation:

$$
\frac{d\left(\Delta V / V_{o}\right)}{d\left(\Delta L / L_{o}\right)}=1-2 v
$$

where $\Delta V / V_{O}$ is the volume strain and $\Delta L / L_{O}(=\epsilon)$ is the elongational strain.

The first part of the curve $(\nu=0.39)$ represents the elastic behaviour. The second part of the volume curve shows that a graph of $\Delta V / V_{o}$ versus $\Delta L / L_{o}$ has almost unit slope (0.97), indicating void formation and crazing as the main yielding mechanism $9,10,11$. The volume drop after failure results from the fact that crazing is a local yielding process: the matrix, elastically strained, recovers after failure of the sample, for the greater part, and forces the voids to close. The accuracy of the slopes of the volume strain curve is within $2-3 \%$. The relative standard deviation of the slopes is $1-2 \%$ for high impact PS samples, whereas this value is about $5 \%$ for the blends in this investigation. This somewhat higher percentage is due to morphological differences from sample to sample.

\section{Materials}

The materials consisting of PS, 1dPE and/or block copoly. mer BC3 were prepared by melt blending between two heated rotating rolls. The PS used was Styron 666 (Dow Chemical) with $M_{n}$ of about 100000 . The low density PE was Stamylan
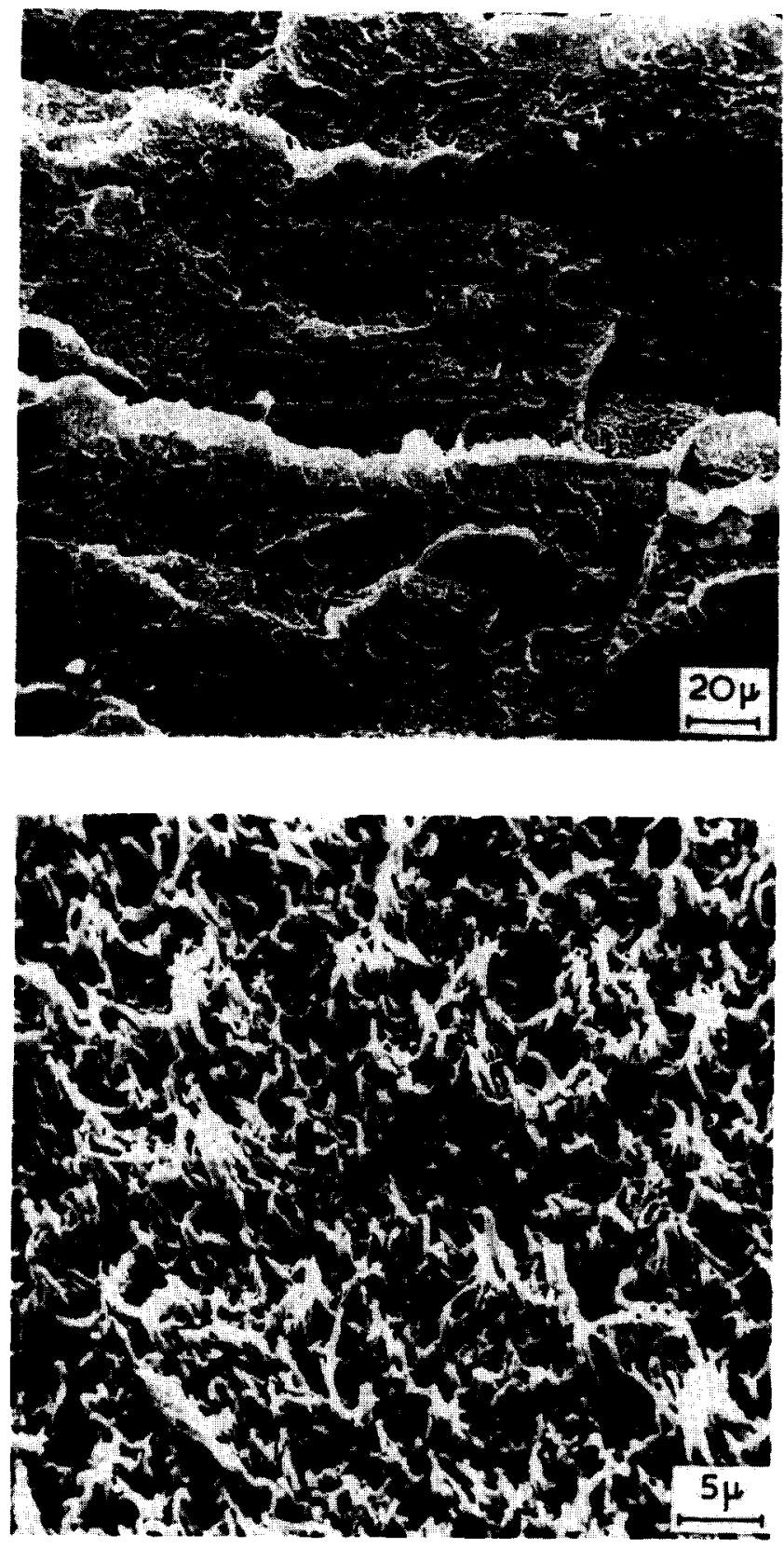

Figure 2 (a) Scanning electron microscope picture of a fracture surface of a blend of PS/BC/IdPE (80/2.25/17.5 by weight) indicating crazing. Unnotched Izod impact strength $5 \times 10^{3} \mathrm{~J} \mathrm{~m}^{-2}$; (b) Scanning electron micrograph of a fracture surface of a blend of PS/BC/ldPE (60/30/10 by weight) indicating microshear. Unnotched Izod impact strength: does not break 


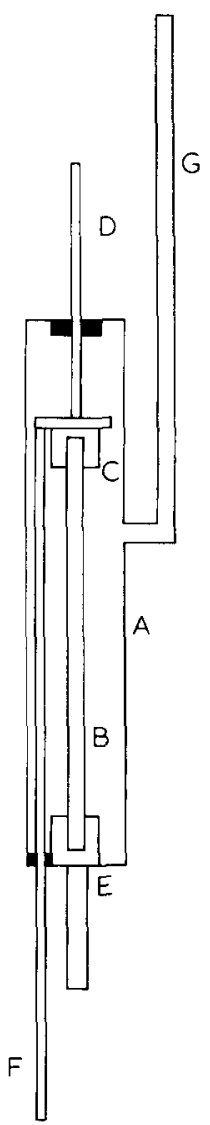

Figure 3 Dilatometer for measuring of volume change of a sample during a tensile test. $A=$ dilatometer vessel filled with water; $B=$ sample; $C=$ stationary clamp; $D=$ bar attached to stress gauge; $E=$ strain bar moving downwards; $F=$ compensation bar with same diameter as bar $D ; G$ = capillary for measuring volume change of sample by following height of water level

1500 (DSM, Holland) with an estimated $M_{n}$ of 30000 to 40000 and a very broad molecular distribution: $M_{w} / M_{n} \approx$ 30. The block copolymer $\mathrm{BC}$ is obtained after hydrogenation of Solprene 410 (Phillips Petroleum Company, USA), which is a linear partial diblock copolymer of PS and $\mathrm{PB}^{1,2}$.

\section{RESULTS AND DISCUSSION}

\section{Presentation of results.}

The results presented here will be for a series of blends containing $7.5,15$ or $25 \%$ by weight of $1 \mathrm{dPE}$ in PS, and for derived series in which $5,30,60$ or $100 \%$ of the free $1 \mathrm{dPE}$ is replaced by bound PE (by adding appropriate amounts of block copolymer BC3 to the blends). Results are presented in Figures 5, 6, 7 and in Tables 1 and 2. They are obtained by averaging the results of five samples of every composition. The results are conveniently discussed by comparing data on blends containing PS and ldPE with those from blends containing PS and block copolymer only. In a latter part blends containing all three components will be considered.

\section{Blends from PS and ldPE}

Blends with 7.5, 15 and 25\% IdPE only (Figures 5, 6 and 7, curves 0 ) have Poisson ratios of $0.33,0.32$ and 0.31 respectively (Table 3). An increase of Poisson ratios should be expected in the case of adhesion between IdPE and PS, as the phase IdPE has, as measured, a high Poisson ratio of 0.48 . That the Poisson ratios become increasingly less with ldPE concentration relative to the Poisson ratio of PS can be explained by micro-void formation around the ldPE particles which do not adhere to the matrix. Such micro-voids, when present before yielding, can be looked upon as craze nuclei.

Now, at the elongation of the sample containing $7.5 \%$ ldPE, where the slope of the stress strain curve $d \sigma / \mathrm{d} \epsilon$ starts to decrease, the slope of volume strain curve $\mathrm{d}\left(\Delta V / V_{o}\right) / \mathrm{d} \epsilon$ starts to increase and becomes about one (Figure 5). It is interesting to note that the change of volume strain rate occurs before yielding. This can be explained as follows: the driving force for the growing of the crazes is the tension in the elastically strained matrix material between the crazes.

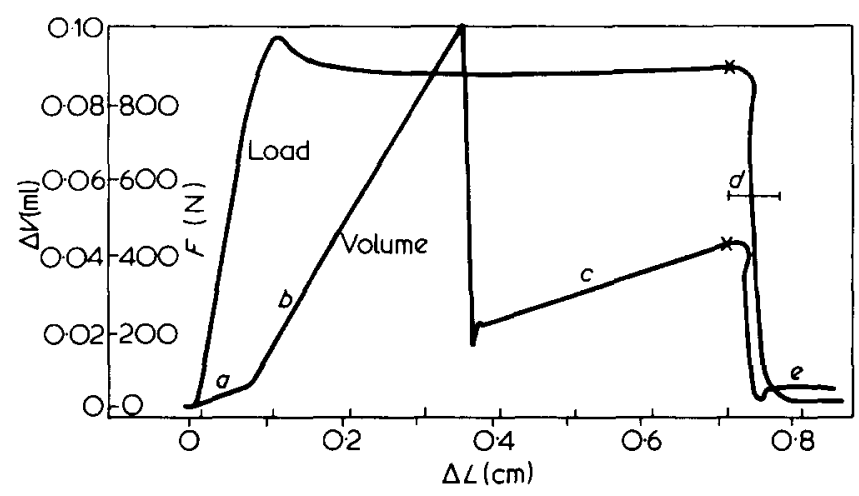

Figure 4 Load $(F)$ and volume change $(\Delta V)$ registered as function of elongation $(\Delta L)$ for high impact PS (Styron 453, Dow Chemical). Strain rate $0.40 \mathrm{~min}^{-1}$. (a) elastic behaviour (b) yielding deformation (crazing) (c) recorder sensitivity reduced (d) failure-registration strongly influence by response features of dilatometer system (e) volume relaxation after failure. The scale of $\Delta V / V$ belongs to part $b$ of the curve

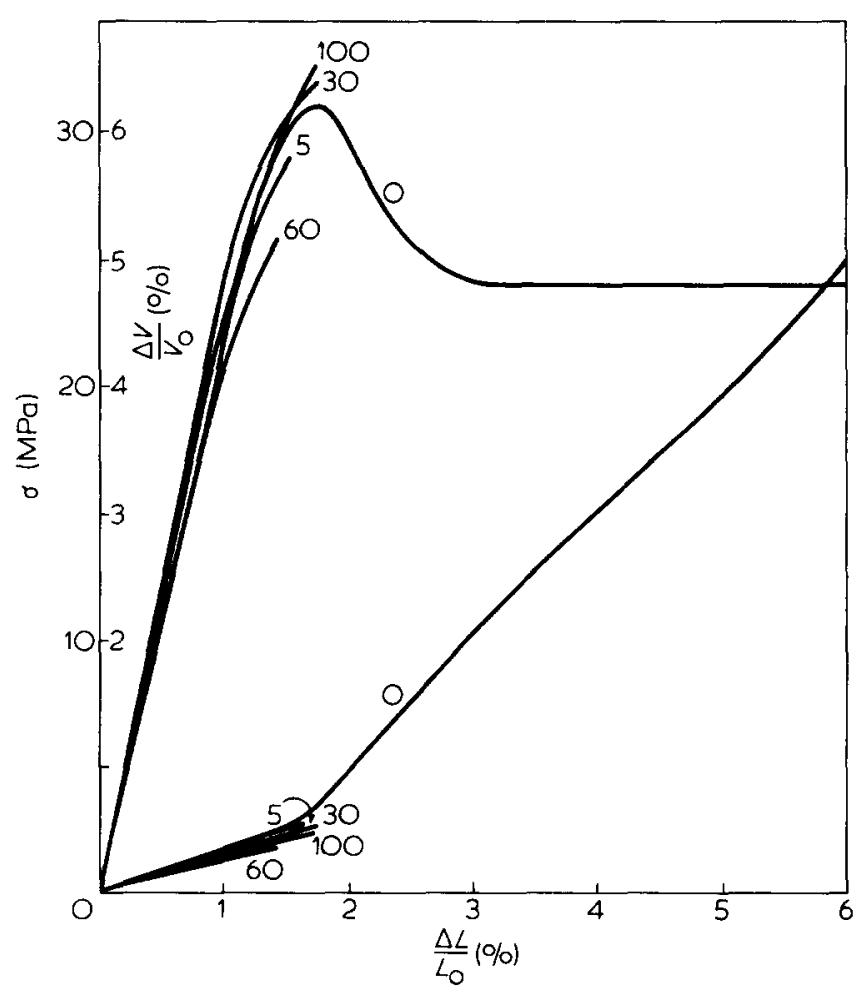

Figure 5 Engineering stress and volume strain measured as function of elongational strain. Curves of PS blends containing in total $7.5 \%$ IdPE. In these blends $0,5,30,60$ and $100 \%$ of free IdPE is replaced by IdPE bound by the block copolymer BC, as indicated by the numbers at the curves 
During elongation the stress rate $\mathrm{d} \sigma / \mathrm{d} \epsilon$ levels off as the craze material takes over part of the elastic strain of the matrix. This explanation implicates that levelling off of the stress rate before the yield-point corresponds to the onset of the craze growing mechanism.

During yielding the slope of the volume strain-elongation strain curve would be expected to be equal to one. The high value found (1.13) indicates that craze formation is not in equilibrium with the rate of elongation. Beyond the yield. point the stress decreases rapidly to a relative small value of $75-80 \%$ of yield stress, reflecting the increase of the volume of the crazes. When the stress has reached a more or less constant value the slope of the volume strain curve goes asymptotically to one, indicating a stationary process between volume strain rate (void content increase) and elongational strain rate.

Comparing the results of samples 5.0,6.0 and 7.0, it is seen that the elongation at break diminishes from 6 to $1 \%$ with increase in ldPE concentration from 7.5 to $25 \%$.

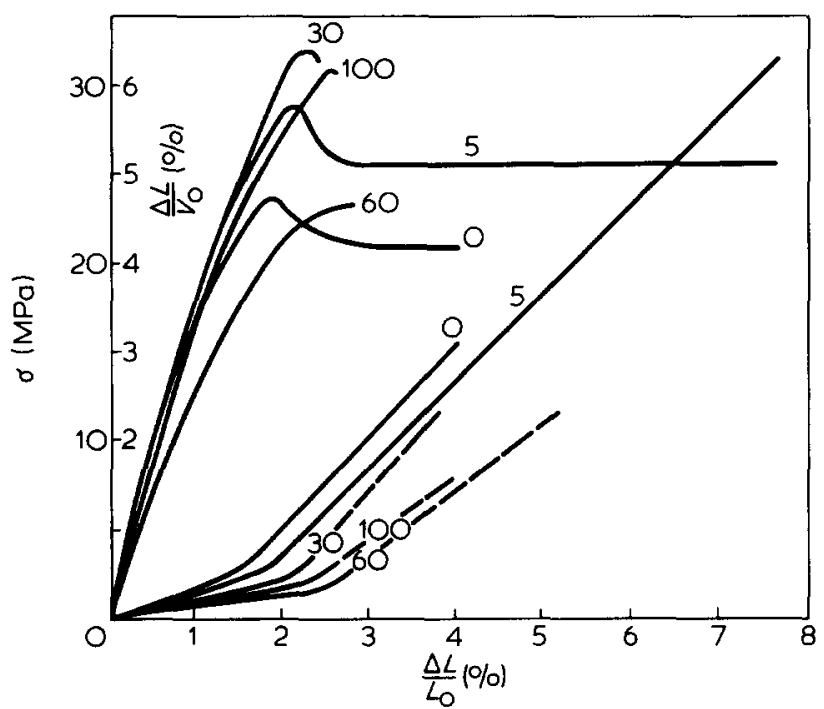

Figure 6 Engineering stress and volume strain measured as function of elongational strain. Curves of PS blends containing in total $15 \%$ IdPE. In these blends 0, 5, 30,60 and 100\% of free IdPE is replaced by IdPE bound by the block copolymer BC, as indicated by the numbers at the curves
The samples with 25\% IdPE 7.0 (Table 3, Figure 7 , number 0 ) breaks even before real yielding occurs. This decrease with increasing ldPE contents can be explained by the increase of the number of crazes, due to the high number of craze initiating ldPE particles. Also the small but significant decrease of the slope of the volume strain curve can be explained by the increase of the number of these particles.

\section{Blends from PS and block copolymer}

The results of these blends will be compared with those from PS and ldPE. Attention will be paid in particular to the effects of adhesion on the Poisson ratio of the blend and on the number of craze nuclei formed by stressing the samples. Adhesion is reflected by the increase of the Poisson ratio from 0.36 to 0.41 and 0.47 at respectively $14.4,29$ and $48 \%$ concentration of block copolymer (Table 1, Figures 4, 6 and 7, curves 100). These copolymer concentrations correspond to bound $1 \mathrm{dPE}$ concentrations of $7.5,15$ and $25 \%$ which can be compared with the samples $5.0,6.0$ and 7.0 with equal concentrations of free ldPE. In the block copolymer-containing blends, copolymer particles will adhere to the matrix and will thus contribute to the

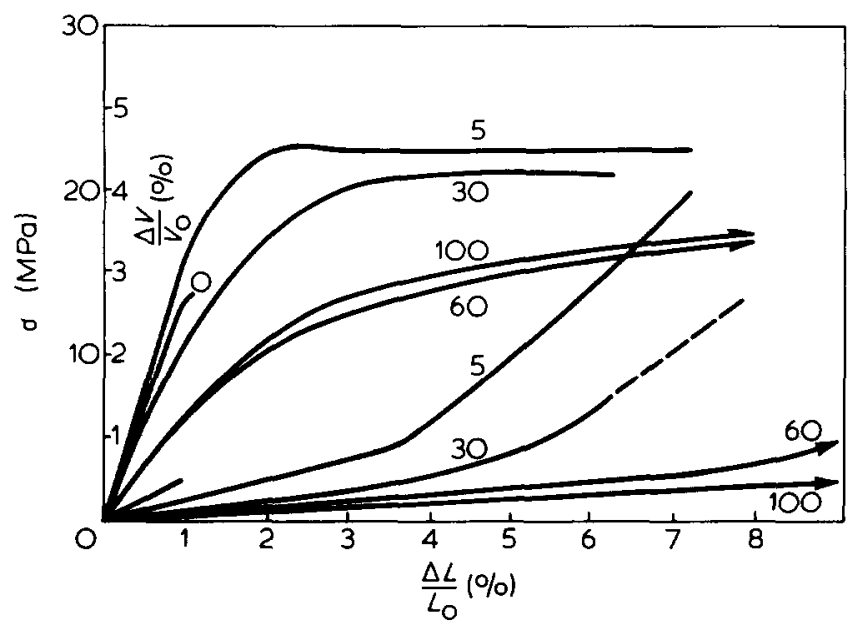

Figure 7 Engineering stress and volume strain measured as function of elongational strain. Curves of PS blends containing in total $25 \%$ of IdPE. In these blends $0,5,30,60$ and $100 \%$ of free IdPE is replaced by IdPE bound by the block copolymer BC, as indicated by the numbers at the curves

Table 1 Comparison of blends containing PS and IdPE and blends containing PS and block-copolymer (BC) with respect to their mechanical data, dilatometric data and deformation mechanism

\begin{tabular}{|c|c|c|c|c|c|c|}
\hline Sample ${ }^{a}$ & $\begin{array}{l}\text { Dispersed } \\
\text { phase }^{b}(w t \%)\end{array}$ & $\epsilon_{y} /(\%) c$ & $\epsilon_{\mathrm{b}} /(\%) \mathrm{c}$ & $\begin{array}{l}\text { Poisson } \\
\text { ratiod }\end{array}$ & Slope & Mechanism $f$ \\
\hline \multicolumn{7}{|c|}{ Blends of PS and IdPE } \\
\hline 5.0 & 7.5 & 1.8 & 6.0 & 0.33 & $1.13-1.04$ & cr. \\
\hline 6.0 & 15.0 & 1.8 & 4.0 & 0.32 & 1.04 & cr. \\
\hline 7.0 & 25.0 & 1.0 & 1.0 & 0.31 & $\mathrm{~g}$ & cr. \\
\hline \multicolumn{7}{|c|}{ Blends of PS and BC3 } \\
\hline 5.100 & 14.4 & 1.7 & 1.7 & 0.36 & $\mathrm{~g}$ & cr. \\
\hline 6.100 & 29.0 & 2.55 & 2.60 & 0.41 & 0.68 & cr. + sh. \\
\hline 7.100 & 48.0 & $\mathrm{~h}$ & 18 & 0.47 & 0.04 & sh. \\
\hline
\end{tabular}

a the first number of this notation refers to Figure 5,6 or 7 . The second number corresponds to the curve numbers in these figures and indicates the percentage of free IdPE being replaced by bound IdPE of the block copolymer; $b$ IdPE plus block copolymer; $c$ elongational strains at vield-point $\left(\epsilon_{Y}\right)$ and at break $\left(\epsilon_{b}\right)$; derived from initial slope of volume strain/elongational strain curve (elastic behaviour); ${ }^{e}$ relates to second part of volume strain/elongational strain curve (yielding behaviou $r) ; \mathrm{fr} .=$ crazing and sh. $=$ shearing; 9 breaks just at yield point; $h$ no stress maximum observed 
Table 2 Mechanical data, dilatometric data and deformation mechanism of PS/block copolymer (BC)/ldPE blends

\begin{tabular}{|c|c|c|c|c|c|c|c|c|}
\hline Samplea & $\begin{array}{l}E \text {-modulus } \\
\times 10^{-2} M P_{a}\end{array}$ & $\begin{array}{l}\text { Total PE } \\
\text { (wt \%) }\end{array}$ & $\begin{array}{l}\text { Dispersed } \\
\text { phase }^{b} \text { (wt \%) }\end{array}$ & $\epsilon_{y} /(\%) c$ & $\epsilon_{\mathrm{b}} /(\%)^{c}$ & $\begin{array}{l}\text { Poisson } \\
\text { ratiod }\end{array}$ & Slope $e^{e}$ & Mechanism \\
\hline 5.5 & 29.3 & 7.5 & 7.9 & $\mathrm{~g}$ & 1.5 & 0.33 & 9 & cr. \\
\hline 5.30 & 23.9 & 7.5 & 9.6 & $\mathrm{~g}$ & 1.7 & 0.34 & $\mathrm{~g}$ & cr. \\
\hline 5.60 & 22.0 & 7.5 & 11.6 & g & 1.4 & 0.37 & $\mathrm{~g}$ & cr. \\
\hline 6.5 & 19.4 & 15.0 & 15.7 & 2.1 & 7.6 & 0.35 & 0.99 & cr. \\
\hline 6.30 & 19.3 & 15.0 & 19.2 & 2.2 & 2.4 & 0.39 & 1.15 & cr. \\
\hline 6.60 & 13.7 & 15.0 & 23.3 & 2.6 & 2.8 & 0.43 & 0.75 & cr. + sh. \\
\hline 7.5 & 15.8 & 25.0 & 26.1 & 2.3 & 7.2 & 0.38 & 0.87 & cr. + sh. \\
\hline 7.30 & 11.2 & 25.0 & 32.0 & 4.5 & 6.3 & 0.44 & 0.67 & cr. + sh. \\
\hline 7.60 & 7.7 & 25.0 & 38.8 & $\mathrm{~h}$ & $>18$ & 0.47 & 0.07 & sh. \\
\hline
\end{tabular}

Explanation of the superior letters in this table as for Table 1

Poisson ratio of the system. As the Poisson ratio of the block copolymer is 0.48 , an increase from 0.36 to 0.41 can be expected on the basis of simple rules of mixtures.

Thus comparison of the results for PS-ldPE and for the PS-block copolymer blends gives a strong indication that the presence of interfacial adhesion can be proved by measurements of the Poisson ratio of these blends. However, at the highest block copolymer concentration (48\%), the block copolymer as observed ${ }^{1,2}$ forms a more or less continuous low modulus phase. The volume change will then be determined almost exclusively by the Poisson ratio of the block copolymer.

Microscopic observation in earlier work ${ }^{2,4}$ showed that adhesion causes a strong reduction in the number of crazes in PS-ldPE blends if some adhesive material like a sequential copolymer is present at the interface.

In the case of PS-block copolymer blends, adhesion between the microphases will be provided for as well and so less crazes will be initiated before the yield stress maximum. With the very small number of crazes present, fatal crack formation in the elastically-strained PS matrix areas can be expected before the yield stress is reached and such a sample breaks brittly. This seems to be the case for the $14.4 \%$ block copolymer containing sample 5.100. At higher concentrations ( $29 \%$ block copolymer, Figure 6 , curve 100 ) more crazes will be formed since more craze initiating particles are present. This results in attainment of a yieldpoint. Even the beginning of a high volume increase beyond the yield-point with a slope of 0.68 indicates that crazing has taken place. Assuming that shear does not produce appreciable volume increase, this value also indicates that shearing contributes $32 \%$ to the yielding deformation, whilst crazing has a contribution of $68 \%$. According to microscopic observation, the block copolymer in this blend forms a semicontinuous network. This network will suppress fatal craze growth by acting as a craze stopper and makes shearing possible since this will probably take place in the low modulus phase. The occurrence of shearing can be shown even better with the sample containing $47 \%$ block copolymer (Figure 7 , curve 100). Here the Poisson ratio is about 0.47 indicating that the deformation is taken over completely by the block copolymer. The very low volume increase with a slope of only 0.04 at high elongations also shows that here shearing is the only mechanism present.

\section{Blends containing PS, ldPE and block copolymer}

The results are presented in Figures 5, 6 and 7 and in Table 2. The mechanical properties of blends containing PS, ldPE and block copolymer are in between the properties of blends from PS and ldPE and blends from PS and block copolymer (Table 1).

Poisson ratio and adhesion. In samples containing $7.5 \%$ of free plus bound ldPE (samples 5.5, 5.30 and 5.60) the ldPE phase will adhere to the matrix due to the presence of block copolymer at the interface. Adhesion is confirmed by the increase of the Poisson ratio from 0.33 to 0.37 where the total percentage of dispersed material increases from 7.911.6. Still higher Poisson ratios are found for the 6 and 7 series as compared with the 5 series.. This must be due to the higher concentrations of disperse phase in these series.

At concentrations higher than about $20-25 \%$ of total dispersed material, semi-continuous or continuous phases of IdPE and block copolymer will be formed. The samples $6.60,7.30$ and 7.60 containing these (semi-) continuous phases have rather low moduli of $13.7-7.7 \times 10^{2} \mathrm{MPa}$ and high Poisson ratios of $0.43-0.47$ as most of the deformation will take place in the low modulus phase.

Thus it may be concluded that adhesion, concentration and morphology strongly determine the values of modulus and Poisson ratio of the blend. At low concentrations of the dispersed particulate phase (samples 5.5, 5.30, 5.60), adhesion can be deduced from the dependence of the Poisson ratio on the concentration. At high concentrations (samples $6.60,7.30,7.60$ ), both modulus and Poisson ratio of the blend are almost completely determined by, respectively, the modulus and the Poisson ratio of the low modulus material due to the formation of the semi-continuous phases.

Brittle-tough behaviour. In describing the brittle-tough behaviour of materials where the yielding deformation takes place by crazing only, the craze density determined by the number of craze nuclei before the maximum yield stress appears to be a crucial parameter. A qualitative relation between resulting craze density and brittle-tough behaviour is shown in Figure 8.

At low craze densities catastrophic cracks are formed, whereas at high craze densities the many crazes unite to cracks. At medium craze densities excessive growing of the crazes is stopped by stress release mechanisms as already pointed out by Nielsen ${ }^{13}$.

In series 5 from 5.5 onward, low concentrations of dispersed material are combined with a good adhesion. As already explained this results in a low number of craze nuclei before the yield stress maximum is reached and accordingly, in a low craze density, bittle failure is found. As an example 5.5 is placed at the low craze density side of the curve of Figure 8. Sample 5.0 containing no block copolymer will 


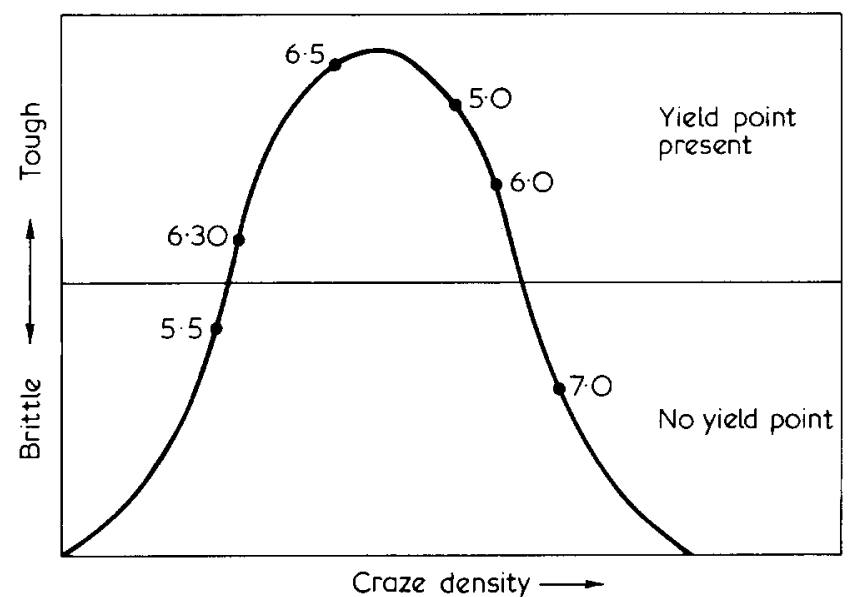

Figure 8 A schematic presentation of the relation between craze density and brittle-tough behaviour. The numbers in the graph refer to the samples in Tables 1 and 2 and to the Figures 5, 6 and 7

have a higher craze density and shows a tough behaviour (Figure 8).

In series 6 (Tables 1 and 2 ) the concentration of dispersed material in the samples $6.0,6.5$ and 6.30 varies only from 15 to $19.2 \%$. As indicated by the slope of the volume strain curve, crazing is the only yielding deformation mechanism. All these samples show a yield-point but their elongation at break varies respectively from 4.0 to 7.6 to $2.4 \%$. In the order $6.0,6.5,6.30$ the particle dimensions decrease and the number of particles increases and one would expect more craze nuclei. As found earlier ${ }^{2,4}$, the formation of crazes is much more strongly reduced by increased adhesion accompanying the reduction of particle sizes. Apparently the samples are qualitatively situated on the curve as shown in Figure 8.

Sample 6.60 , containing $24 \%$ soft material, shows some shearing $(24 \%)$ due to the onset of semi-continuous phase formation. This will have the tendency to enhance the elongation at break. But at the same time craze formation will be suppressed by adhesion, thus lowering the elongation at break. The net result here is that the material breaks just beyond the yield-point.

In series 7 the high concentration of dispersed material $(>26 \%)$ enhances shearing from sample 7.5 to 7.60 as shown by the decreased slope of the volume curve. The elongation at break will increase by the formation of a semi-continuous phase. This phase will act as a craze stopper in all three samples and thus even in sample 7.5 , which still deforms $87 \%$ by crazing, catastrophic crazing cannot occur at low elongation. If shearing is the only deformation mechanism (sample 7.60) a high Poisson ratio is combined with a low slope of the volume strain curve and a very low modulus. In this sample deformation takes place in the continuous low modulus phase only.

\section{GENERAL CONCLUSIONS}

During a tensile test, soft particles (IdPE and/or block copolymer) dispersed in a stiff matrix (PS) can cause crazing.
At higher concentrations the soft phase tends to a more or less continuous phase and yielding will take place by shearing. At intermediate compositions a combination of both mechanisms can occur.

In blends where the occurrence of shearing can be excluded, a low craze density causes brittle failure. However, a high craze density also causes brittle behaviour, as the many crazes now run into each other, and so tough behaviour can be expected at intermediate craze densities. The craze density will be determined by the number of craze nuclei before the yield stress maximum is reached. The number of craze nuclei is governed by the number of soft phase particles and is high at low adhesion forces between the particles and the matrix. Addition of block copolymer to the blends increases the number of particles by emulsifying action; however the ease of formation of nuclei is now reduced and overcompensates the increase in the number of particles. The state of adhesion can be deduced from the experimentally determined dependence of the Poisson ratio on the concentration of the soft material. Higher concentrations of the soft low modulus material will lead to formation of a more or less continuous phase and in this case the phase borders will act as craze stoppers.

However, shearing can occur in the low modulus phase and rather large elongations at break can result. By choosing the correct ratio of block copolymer and low modulus polymer (added in suitable concentration to the stiff polymer), attractive combinations of modulus and toughness are attainable.

\section{ACKNOWLEDGEMENTS}

The assistance of Mr. J. Boekholt and Mr. P. J. Broers in constructing the dilatometer is gratefully acknowledged.

\section{REFERENCES}

1 Hoen, N. 'Graft copolymers by means of a reaction between polyethylene and polystyrene and their modifying effect in homopolymer blends' Thesis, Eindhoven, 1977 (in English)

2 Heikens, D., Hoen, N., Barentsen, W., Piet, P. and Ladan, H. J. Polym. Sci., Polym. Symp. 1978, 61, 309

3 Barentsen, W. M. and Heikens, D. Z. Werkstofftech. 1970, 1, 49

4 Barentsen, W. M. 'Some mechanical properties of polymer blends' Thesis, Eindhoven, 1972 (in Dutch)

5 Barentsen, W. M. and Heikens, D. Polymer 1973, 14, 579

6 Barentsen, W. M., Heikens, D. and Piet, P. Polymer 1974, 15, 119

7 Heikens, D. and Barentsen, W. M. Polymer 1977, 18, 69

8 Barentsen, W. M., Heijdenrijk, P. J., Heikens, D. and Piet, P. Br. Polym. J. 1978, 10, 17

9 Bucknall, C. B. and Clayton, D. Nature (London), Phys. Sci. $1971,231,107$

10 Bucknall, C. B. and Clayton, D. J. Mater. Sci. 1972, 7, 202

11 Bucknall, C. B. 'Toughened Plastics', Applied Science, London, 1977, Chapter 7

12 Breuer, H., Haaf, F. and Stabenow, J. J. Macromol. Sci. Phys. $1977,14,387$

13 Nielsen, L. E. 'Mechanical Properties of Polymers', Reinhold, New York, 1963, p 133 